\title{
Unicuspid aortic valve and infective endocarditis
}

\author{
Pau Vilardell ${ }^{1}$, Sergio Moral ${ }^{1}$, Manel Morales ${ }^{1}$, Esther Ballesteros ${ }^{2}$, and Ramon Brugada ${ }^{1}$ \\ ${ }^{1}$ Doctor Josep Trueta University Hospital of Girona \\ ${ }^{2}$ Radiology department, Centre d'atenció Primària Pare Claret, Institut Català de la Salut, \\ Barcelona, Spain
}

January 11, 2021

\begin{abstract}
Abstract Unicuspid aortic valve (UAV) is a rare congenital malformation, related to an aggressive evolution of valve function. Its diagnosis represents an important cardiac imaging challenge, since it is often difficult to differentiate between other anomalies like bicuspid aortic valve. Recently, bicuspid aortic valve has been associated with IE, especially when aortic valve function shows significant stenosis, however, the relationship between IE and UAV is unclear. The anatomical characteristics of UAV could predispose to IE. This report describes a young patient affected by infective endocarditis (IE) with UAV and the case reviews the echocardiographic criteria used to improve its management.
\end{abstract}

TITLE PAGE

Article Title:

UNICUSPID AORTIC VALVE AND INFECTIVE ENDOCARDITIS

List of Authors and Academic Degrees: Pau Vilardell, MD (1), Sergio Moral, MD, PhD (1), Manel Morales, MD (1), Esther Ballesteros, MD (2), Ramon Brugada, MD, PhD (1,3,4).

List of Authors' Affiliations:

1. Cardiology Department, Hospital Universitari Doctor Josep Trueta, Girona, Spain

2. Radiology Department, Centre d’Atenció Primaria Pare Claret, Institut Català de la Salut, Barcelona, Spain

3. Cardiovascular Genetics Centre, University of Girona-IDIBGI; Medical Science Department, School of Medicine, University of Girona, Girona, Spain

4. Centro Investigación Biomédica en Red: Enfermedades Cardiovasculares (CIBERCV), Madrid, Spain

\section{Corresponding Author's Contact Info:}

Sergio Moral, MD, PhD Cardiology Department, Hospital Universitari Doctor Josep Trueta Avenida França, S/N, 17007, Girona, Spain Phone: +34 972940200; FAX: +34 972940270 E-mail:moral.sergio@yahoo.es

Potential Conflicts of Interest: None.

Total Word Count: 1149 words

\section{Abstract}

Unicuspid aortic valve (UAV) is a rare congenital malformation, related to an aggressive evolution of valve function. Its diagnosis represents an important cardiac imaging challenge, since it is often difficult to differentiate between other anomalies like bicuspid aortic valve. Recently, bicuspid aortic valve has been associated with IE, especially when aortic valve function shows significant stenosis, however, the relationship between 
IE and UAV is unclear. The anatomical characteristics of UAV could predispose to IE. This report describes a young patient affected by infective endocarditis (IE) with UAV and the case reviews the echocardiographic criteria used to improve its management.

\section{Keywords}

Infective endocarditis

Aortic valve

Echocardiography
Abreviations
BAV: Bicuspid aortic valve
IE: Infective endocarditis
TEE: Transesophageal echocardiography
TTE: Transtorachic echocardiography
UAV: Unicuspid aortic valve

\section{Introduction}

Unicuspid aortic valve (UAV) is an infrequent congenital anomaly secondary to altered aortic cusp development from tubercles ${ }^{1}$. A disordered number of cusps results from fusion or duplication, with a reported occurrence with echocardiography of $1 \%$ for bicuspid aortic valve (BAV), $0.05 \%$ for quadricuspid aortic valve, and $0.02 \%$ for $\mathrm{UAV}^{2}$. Due to its rarity, clinical progression and complications of UAV are not well known.

\section{Case Report}

A 34-year-old woman with a two-week history of fever presented to the emergency department because of sudden-onset mild right hemiparesis and dysarthria. Computed tomography scan demonstrated a left thalamic stroke. Her symptoms rapidly resolved, thus intravenous thrombolysis was not prescribed. Blood tests revealed leukocytosis and elevated C-reactive protein levels. Cardiac systolic murmur was patent, and transthoracic echocardiography (TTE) showed an UAV with moderate aortic stenosis without regurgitation or aortic dilation. An irregular vibrated mass was also identified and transesophageal echocardiography (TEE) confirmed the presence of $6 \times 8-\mathrm{mm}$ vegetation attached to the aortic valve (Figure 1A; arrows). Blood cultures showed Staphylococcus epidermidis, supporting a diagnosis of infective endocarditis (IE). After two weeks of medical treatment, aortic valve replacement was indicated for persistent vegetation after an embolic episode. Direct surgical inspection of the aortic valve confirmed a stenotic UAV. No postoperative complications occurred, and the patient was discharged after finishing the antibiotic therapy.

\section{Discussion}

UAV is a rare congenital malformation, resulted from the abnormal fusion ot the three tubercles. The true prevalence of UAV is unknown and likely underestimated, since it is often difficult to differentiate between other anomalies like BAV by cardiac imaging ${ }^{3,4}$. Further, $>50 \%$ of UAV cases are only confirmed by intraoperative surgery or autopsy ${ }^{5}$. Two phenotypes of UAV have been described in the literature, the unicommisural type with a single leaflet from the aortic wall and one being the pinhole-shaped acomissural $\mathrm{UAV}^{6,7}$. Four echocardiographic criteria are used to improve the differential diagnosis ${ }^{8}$ : (i) single commissural attachment zone, (ii) rounded leaflet-free edge on the opposite side of the commissural attachment zone, (iii) eccentric valvular orifice during systole and (iv) age $<20$ years and mean transvalvular gradient $>15 \mathrm{mmHg}$. When three of them are met, they have $97 \%$ specificity for diagnosing of UAV (Figure 1B; Videos 1-4). Clinically, UAV presents a more aggressive evolution during follow-up than BAV-the valve is rarely normofunctional and generates earlier significant aortic stenosis and more aortic valve intervention associated with ascending aortic aneurysm repair via the Bentall procedure than in BAV patients ${ }^{5,9}$. 
Recently, BAV has been associated with IE, especially when aortic valve function shows significant stenosis ${ }^{10}$. This new evidence challenges the recommendations of antibiotic prophylaxis in BAV patients undergoing dental procedures. The high-risk profile of UAV for developing aortic complications highlight the differential diagnosis between both entities and the potential risk of IE should raise the question if antibiotic prophylaxis may be also recommended in these patients.

\section{Declaration of interests}

The authors declare that they have no known competing financial interests or personal relationships that could have appeared to influence the work reported in this paper.

\section{Funding Source}

No funding source. Nothing to declare.

\section{Ethical Approval}

We anonymize all images and data.

\section{REFERENCES}

1. Suraci N, Lo Presti S, D'Mello J, Xydas S, Mihos CG. Unicuspid aortic valve: Case series and review. Echocardiography . 2020;(September):1-5. doi:10.1111/echo.14885

2. Slostad BD, Witt CM, O'Leary PW, et al. Diagnostic Accuracy of Echocardiography and Intraoperative Surgical Inspection of the Unicuspid Aortic Valve. Am J Cardiol . 2019;123(6):967-971. doi:10.1016/j.amjcard.2018.12.010

3. Slostad BD, Witt CM, O'Leary PW, et al. Unicuspid Aortic Valve.Circulation . 2019;140:1853-1855. doi:10.1161/CIRCULATIONAHA.119.041835

4. Armstrong J, Crawford J, Arnautovic J. Unicuspid aortic valve replacement with development of complete heart block: A case report.Eur Hear J - Case Reports . 2019;3(1):1-6. doi:10.1093/ehjcr/ytz026

5. Roberts WC, Vowels TJ, Ko JM. Natural History of Adults With Congenitally Malformed Aortic Valves ( Unicuspid or Bicuspid ).Medicine (Baltimore) . 2012;91(6):287-308. doi:10.1097/MD.0b013e3182764b84

6. Mookadam F, Thota VR, Garcia-lopez AM, et al. Unicuspid Aortic Valve in Adults : A Systematic Review. J Hear Valve Dis . 2010;1(19):79-85.

7. Tempe DK, Garg M, Tomar AS, Dutta D, Dutta R, Singh AK. Unicuspid Aortic Valve: Transesophageal Echocardiographic Features. $J$ Cardiothorac Vasc Anesth . 2012;26(2):277-279. doi:10.1053/j.jvca.2011.01.011

8. Ewen S, Karliova I, Weber P, et al. Echocardiographic criteria to detect unicuspid aortic valve morphology. Eur Heart J Cardiovasc Imaging . 2019;20:40-44. doi:10.1093/ehjci/jex344

9. Ma LE, Vali A, Blanken C, Barker AJ, Schnell S, Markl M. Altered Aortic 3D Hemodynamics in Patients with Functionally Unicuspid Aortic Valves. Circ Cardiovasc Imaging . 2018;11(8):1-5. doi:10.1161/CIRCIMAGING.118.007915.

10. Zegri-reiriz I, Miro JM, Falces C, et al. Infective Endocarditis in Patients With Bicuspid Aortic Valve or Mitral Valve Prolapse. J Am Coll Cardiol . 2018;71(24):2731-2740. doi:10.1016/j.jacc.2018.03.534

\section{FIGURE LEGENDS}

Figure 1A. Transesophageal echocardiography assessment of unicuspid aortic valve. Upper left, Mid-esophageal 2D short-axis transesophageal echocardiography view of the aortic valve. LA, Left atrium; PV, Pulmonic valve; TV, Tricuspid valve. Upper right,Mid-esophageal 3D short-axis transesophageal echocardiography view of the aortic valve. LA, Left atrium; PV, Pulmonic valve; TV, Tricuspid valve. Lower left, Mid-esophageal 2D long-axis transesophageal echocardiography view of the aortic valve, showing the 
vegetation (yellow arrow). AA, Ascending aorta; LVOT, Left ventricular outflow tract. Lower right, Midesophageal 3D long-axis transesophageal echocardiography view of the aortic valve, showing the vegetation (yellow arrow). AA, Ascending aorta.

Figure 1B. Schematic of echocardiographic features to detect unicuspid aortic valve morphology. Four criteria can be used to detect unicuspid aortic valve: (I) mean aortic transvalvular gradient $>15$ $\mathrm{mmHg}$ and patient age of $<20$ years, (II) single commissural zone of attachment, (III) eccentric valvular orifice during systole, and (IV) rounded leaflet-free edge on opposite side of the commissural attachment zone.

\section{Acknowledgements}

None 

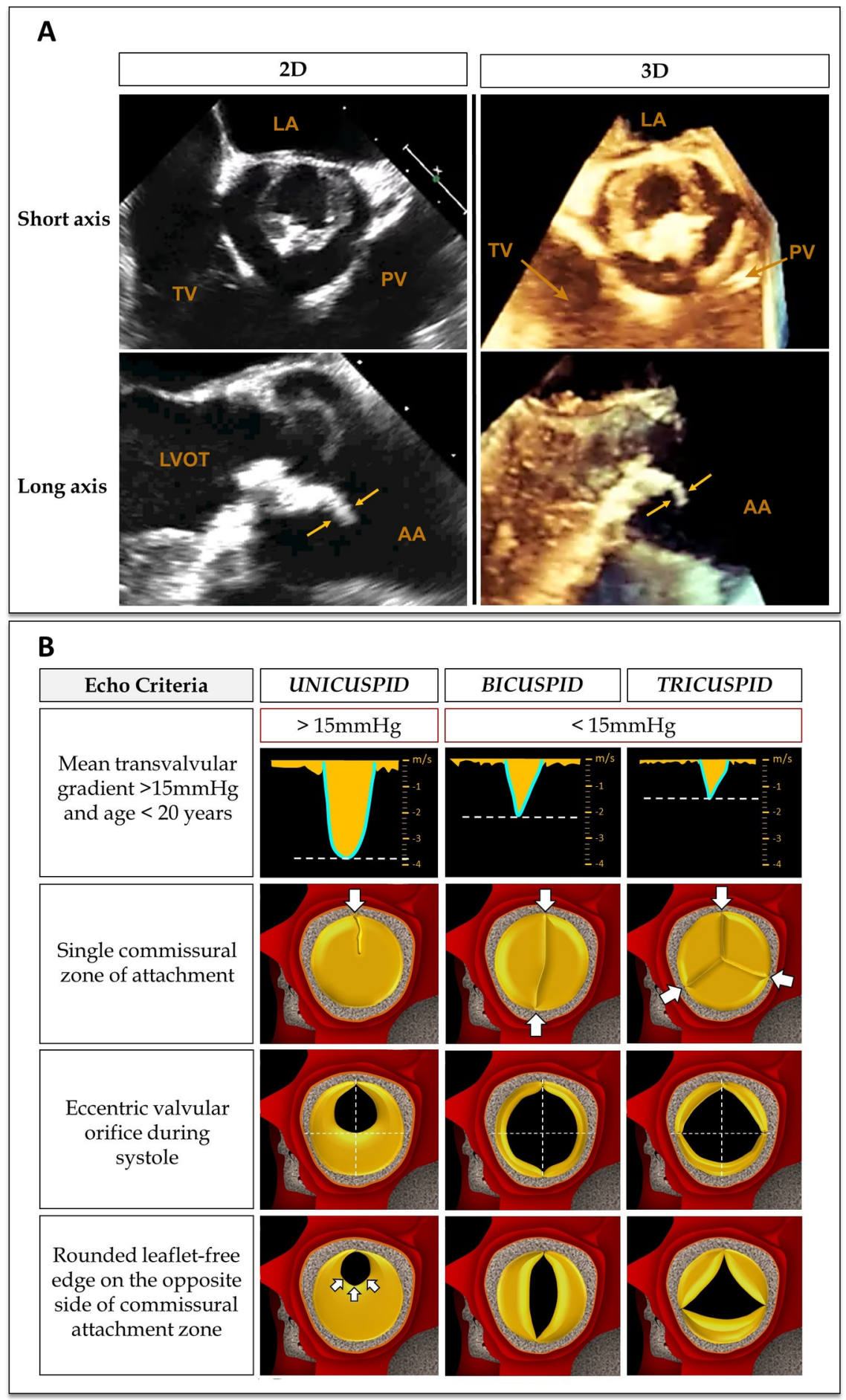